\title{
Development and validation of RP-HPLC-PDA method for the quantification of eugenol in developed nanoemulsion gel and nanoparticles
}

Kannissery Pramod ${ }^{1}$, Ura Kottil llyas ${ }^{2}$, Yoonuskunju Thajudeenkoya Kamal ${ }^{2}$, Sayeed Ahmad², Shahid Hussain Ansari ${ }^{2}$ and Javed $\mathrm{Ali}^{i^{*}}$

\begin{abstract}
Background: Eugenol is a potent phytochemical, and a plethora of delivery systems for this bioactive agent is being developed. Reversed-phase high-pressure liquid chromatography equipped with photodiode array detector (RP-HPLC-PDA) method is very useful in the quantification of the phytochemicals.

Methods: The RP-HPLC-PDA system with C18 reversed-phase column $(250 \times 4.6 \mathrm{~mm}$, particle size $5 \mu \mathrm{m})$ was used in this study. Acetonitrile and water in 1:1 $(\mathrm{v} / \mathrm{V})$ ratio was chosen as the mobile phase under a column temperature of $25^{\circ} \mathrm{C}$. The detection wavelength was set at $280 \mathrm{~nm}$ with a flow rate of $1 \mathrm{~mL} / \mathrm{min}$. Method validation was performed according to the International Conference on Harmonization guidelines.

Results: HPLC method for the quantification of eugenol was successfully developed and validated. The method was validated in terms of linearity and range, accuracy, precision, specificity, robustness, detection limit, and quantitation limit.
\end{abstract}

Conclusions: The developed RP-HPLC-PDA could be successfully employed for the quantification of eugenol in nanoemulsion gel and nanoparticles.

Keywords: Accuracy; Precision; Specificity; Robustness; ICH guidelines

\section{Background}

A good number of novel delivery systems of eugenol (Chen et al. 2009; Gomes et al. 2011; Jadhav et al. 2004; Kriegel et al. 2010; Pokharkar et al. 2011) have been reported owing to its potent bioacitivity. Antiinflammatory and anti-microbial actions are among other major pharmacological actions of eugenol (Pramod et al. 2010). Development of a suitable analytical method will be needed when eugenol is formulated in nanocarriers for targeted delivery.

Quantification of the pharmacologically active component in a dosage form is indispensable to the quality control of these systems. Quality control checks the suitability of a drug delivery system for the intended application. It serves as a marker for the consistency

\footnotetext{
* Correspondence: javedaali@yahoo.com

${ }^{1}$ Department of Pharmaceutics, Faculty of Pharmacy, Jamia Hamdard, Hamdard Nagar, New Delhi - 110 062, India

Full list of author information is available at the end of the article
}

and predictability of the performance of dosage forms (Levi et al. 1964). High-pressure liquid chromatography (HPLC) methods are widely reported for the quantitative estimation of bioactive phytochemicals, but to this day, no reports are available on reversed-phase HPLC equipped with photodiode array detector (RP-HPLCPDA) methods for the quantification of eugenol in nanostructured delivery systems such as nanoemulsion gel and nanoparticles. Besides this, none of the methods are available for eugenol quantification from formulations where a high specificity is required to overcome the probable interference of the excipients.

Nanoemulsion gel and nanoparticles have been developed as novel drug delivery systems of eugenol (Pramod et al. 2012, 2013). The major aim of the present work was to develop a RP-HPLC-PDA method for the quantitative estimation of eugenol in these drug delivery systems for anti-inflammation and periodontal infection. 


\section{Methods}

\section{Chemicals and reagents}

Eugenol (pure) was purchased from Central Drug House (Delhi, India). Poly- $\varepsilon$-caprolactone (MW 14,000), chitosan, sodium alginate and Pluronic F-68 were purchased from Sigma-Aldrich Co. (MO, USA). Tween 80 and polyvinyl alcohol were purchased from Central Drug House (New Delhi, India). Carbopol 940 was a gift sample from Noveon Corporation (Cleveland, OH, USA). Tween 80 and triethanolamine were purchased from S D Fine-Chem Ltd. (Mumbai, India). Ethanol (99.9\%) was purchased from Jiangsu Huax Co., Ltd. (Jiangsu, China). HPLC-grade water and acetonitrile were purchased from Merck (Mumbai, India).

\section{Preparation of eugenol-loaded nanoemulsion gel and nanoparticles}

Aqueous titration method was employed for the preparation of eugenol-loaded nanoemulsion. The formulated eugenol-loaded nanoemulsion was converted to nanoemulsion gel by dispersing $1 \%(w / w)$ Carbopol 940 in it. Tween 80 and ethanol were used as surfactant and co-surfactant, respectively. For $S_{\text {mix }}$, a specific volume ratio of 4:1 (Tween 80/ethanol) was used (Pramod et al. 2012). For the preparation of the sample solution of nanoemulsion gel, an accurately weighed gel sample was taken in methanol, sonicated (Altrasonics, Mumbai, India) for $20 \mathrm{~min}$, and filtered using a $0.2-\mu \mathrm{m}$ syringe filter (Axiva Sichem Biotech, New Delhi, India).

Solvent displacement method was employed for the preparation of eugenol-loaded nanoparticles (Reis et al. 2006). Polycaprolactone (encapsulating polymer) and eugenol were dissolved in acetone (organic solvent phase) by mild heating. The solution of eugenol and polymer was injected dropwise into aqueous Pluronic F-68 (stabilizer) solution under magnetic stirring, and stirring was continued until complete evaporation of acetone occurred. Centrifugation of the suspension of nanoparticles thus obtained was carried out at 15,000 rpm for $1 \mathrm{~h}$. The obtained nanoparticles were washed twice with distilled water and then freeze-dried (Pramod et al. 2013). For the preparation of the sample solution from nanoparticles, accurately weighed sample of dried nanoparticles was dissolved in $1 \mathrm{~mL}$ of acetone and then was added to $5 \mathrm{~mL}$ of methanol. Acetone was then evaporated. The sample was sonicated (Altrasonics, Mumbai, India) for $20 \mathrm{~min}$, then was made up to $10 \mathrm{~mL}$ with methanol, and was filtered using a $0.2-\mu \mathrm{m}$ syringe filter (Axiva Sichem Biotech, New Delhi, India) (Pramod et al. 2013).

\section{HPLC instrumentation and chromatographic conditions}

The HPLC method for the determination of eugenol was carried out on a Waters Alliance e2695 separating module (Waters Co., MA, USA) using a photodiode array detector (Waters 2998) with autosampler and column oven. The instrument was controlled by Empower 2 software (Europa Science, Ltd., Cambridge, UK) installed with equipment for data collection and acquisition. Compounds were separated on a C18 reversed-phase column $(250 \times 4.6 \mathrm{~mm}$, particle size $5 \mu \mathrm{m}$; Merck, Darmstadt, Germany) maintained at room temperature.

\section{Mobile phase}

Acetonitrile and water in the ratio of 1:1 $(v / v)$ was chosen as the mobile phase.

\section{Chromatographic system}

The chromatographic system is composed of the following (Table 1): Chromatographic conditions.

\section{Preparation of the mobile phase}

HPLC-grade water was mixed with HPLC-grade acetonitrile in the volume ratio of 1:1. The prepared mobile phase was then filtered through a $0.45-\mu \mathrm{m}$ nylon filter and sonicated in an ultrasonic bath for $15 \mathrm{~min}$.

\section{Method validation \\ Linearity and range}

A stock solution of eugenol $\left(10 \mathrm{mg} \mathrm{mL} \mathrm{m}^{-1}\right)$ was prepared in methanol. Standard calibration solutions (5 to $1,000 \mu \mathrm{g} \mathrm{mL}^{-1}$ ) for the assessment of linearity were prepared from this stock solution using the mobile phase. The solutions were filtered through a $0.45-\mu \mathrm{m}$ nylon filter. The filtered solution was then injected into the HPLC system. The data of peak area versus drug concentration were treated by linear least square regression.

\section{Accuracy as recovery}

Accuracy was determined by recovery studies using standard addition method. The pre-analyzed samples were spiked with extra $50 \%, 100 \%$, and $150 \%$ of the standard

\section{Table 1 Chromatographic conditions}

\begin{tabular}{|c|c|}
\hline Composition & Value \\
\hline Column & $\begin{array}{l}\text { C18 reverse phase column }(250 \times 4.6 \mathrm{~mm} \text {, } \\
\text { particle size } 5 \mu \mathrm{m} \text {; Merck, Darmstadt, Germany) }\end{array}$ \\
\hline Flow rate & $1 \mathrm{~mL} \min ^{-1}$ \\
\hline Retention time & $7.968 \pm 0.042 \mathrm{~min}$ \\
\hline Detector & PDA detector (Waters 2998) \\
\hline Detection wavelength & $280 \mathrm{~nm}$ \\
\hline Injection volume & $20 \mu \mathrm{L}$ \\
\hline Temperature & $25^{\circ} \mathrm{C}$ \\
\hline Elution type & Isocratic \\
\hline Run time & $20 \mathrm{~min}$ \\
\hline
\end{tabular}




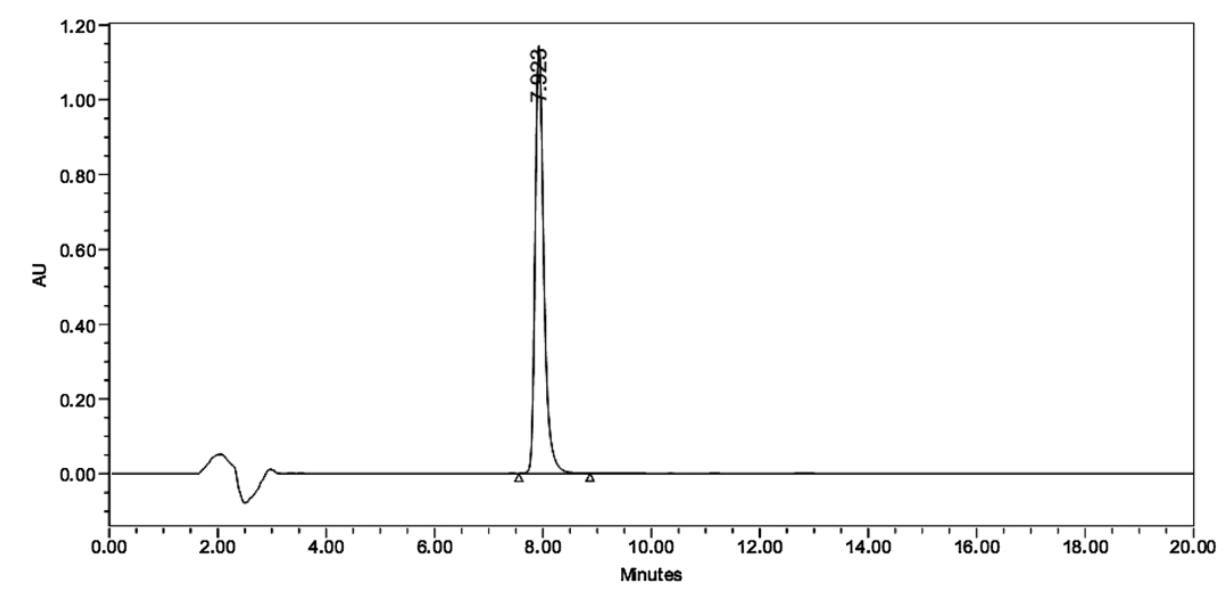

Figure 1 HPLC chromatogram of eugenol.

eugenol, and the mixtures were analyzed by the proposed method. The experiment was conducted in triplicate.

\section{Precision}

The intraday (repeatability) and interday (intermediate precision) variations for the determination of eugenol was carried out at three concentration levels of 20, 100, and $600 \mu \mathrm{g} \mathrm{mL} L^{-1}$. The determinations were carried out in triplicate.

\section{Specificity}

The specificity of the method was ascertained by analyzing the standard drug and sample. The band for eugenol in nanoemulsion gel and nanoparticle samples was confirmed by comparing the $R_{\mathrm{f}}$ values and spectra of the band with that of the standard. The peak purity of eugenol was assessed by comparing the spectra at three different levels, that is, peak start, peak apex, and peak end positions of the spectrum.

\section{Robustness}

Robustness of the method was carried out by introducing very small changes in the analytical methodology at

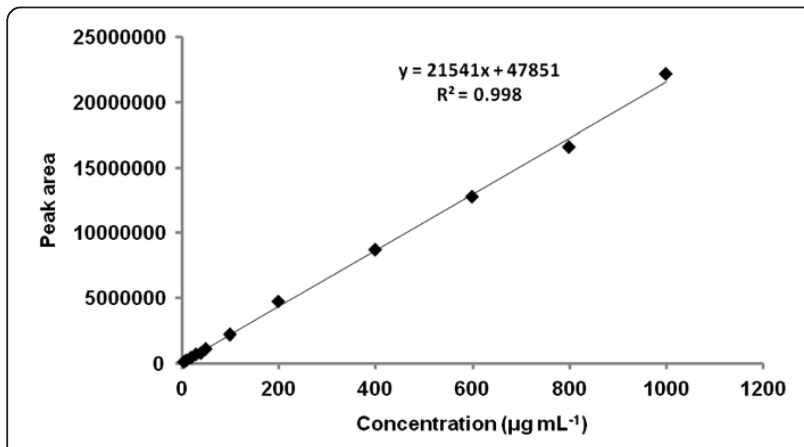

Figure 2 Calibration curve of eugenol by HPLC method. a single concentration level $\left(100 \mu \mathrm{g} \mathrm{mL} \mathrm{m}^{-1}\right)$. Robustness of the proposed method was determined in two different ways, i.e., by making deliberate changes in the mobile phase ratio, flow rate, and detection wavelength of analysis. The percentage of relative standard deviation (\%RSD) of the experiment was calculated to assess the robustness of the method.

\section{Detection and quantitation limits}

The detection limit (DL) is the lowest amount of analyte in a sample, which can be detected but not necessarily quantitated. The quantitation limit $(\mathrm{QL})$ is the lowest amount of analyte in a sample, which can be quantitatively determined with suitable precision and accuracy. The limit of quantification and limit of detection were determined based on the technique of signal-to-noise ratio (ICH Guidelines Q2(R1) 2005) using Equations 1 and 2:

$$
\begin{aligned}
& \mathrm{QL}=10 \sigma / S \\
& \mathrm{DL}=3.3 \sigma / S
\end{aligned}
$$

where $\sigma$ is the standard deviation of the intercept of the calibration plot and $S$ is the slope of the calibration curve.

\section{Results and discussion}

Although limited HPLC methods for the determination of eugenol have been reported (Dighe et al. 2005; Li

Table 2 Linear regression data for the calibration curve $(n=3)$

\begin{tabular}{ccc}
\hline Parameter & Mean \pm SD & \%RSD \\
\hline Linearity range $\left(\mu \mathrm{gL}^{-1}\right)$ & 5 to 1,000 & - \\
Correlation coefficient $\left(R^{2}\right)$ & $0.9984 \pm 0.0001$ & 0.02 \\
Slope & $215,40.54 \pm 63.93$ & 0.30 \\
Intercept & $47,851.22 \pm 2,880.31$ & 6.02 \\
\hline
\end{tabular}


Table 3 Recovery data for the accuracy of the HPLC method

\begin{tabular}{|c|c|c|c|c|c|}
\hline $\begin{array}{l}\text { Excess of eugenol } \\
\text { added (\%) }\end{array}$ & $\begin{array}{l}\text { Concentration of } \\
\text { sample }\left(\mu \mathrm{g} \mathrm{mL}^{-1}\right)\end{array}$ & $\begin{array}{l}\text { Theoretical concentration } \\
\text { of spiked sample }\left(\mu \mathrm{g} \mathrm{mL}^{-1}\right)\end{array}$ & $\begin{array}{c}\text { Concentration of spiked } \\
\text { sample } \pm S D\left(\mu \mathrm{gL}^{-1}\right)(n=3)\end{array}$ & Recovery \pm SD (\%) & \%RSD \\
\hline 50 & 100 & 150 & $149.41 \pm 1.87$ & $99.60 \pm 1.24$ & 1.25 \\
\hline 100 & 100 & 200 & $202.15 \pm 1.36$ & $101.07 \pm 0.68$ & 0.67 \\
\hline 150 & 100 & 250 & $252.01 \pm 1.82$ & $100.80 \pm 0.73$ & 0.72 \\
\hline
\end{tabular}

et al. 2004), none of them reported their specificity in quantifying eugenol in nanostructured delivery systems. Moreover, the application of PDA detector is an added advantage for the developed method. Detection of an entire spectrum simultaneously is possible with PDA detector. While UV-vis detectors visualize the obtained result in two dimensions (light intensity and time), only PDA adds the third dimension (wavelength). This is convenient to determine the most suitable wavelength without repeating analyses. No methods are available for eugenol quantification from formulations where a high specificity is required to overcome the probable interference of the excipients.

\section{Calibration curve}

A representative chromatogram of eugenol in the developed HPLC method is shown in Figure 1. A retention time of 7.923 min can be observed from the HPLC chromatogram in Figure 1. The calibration curve for eugenol by the developed HPLC method is shown in Figure 2. The linear regression data for the calibration curve demonstrated a good linear relationship over the concentration range of 5 to $1,000 \mu \mathrm{g} \mathrm{mL}^{-1}$. A good linearity was established by a correlation coefficient $\left(R^{2}\right)$ value of $0.9984 \pm 0.0001$ (Table 2). Correlation coefficient is a statistical tool used to measure the degree or strength of this type of relationship, and here, a high correlation coefficient value (a value very close to 1.0) indicates a high level of linear relationship between the concentration of eugenol and peak area. No significant differences were observed in the slopes of standard curves as indicated by the low \%RSD of 0.30 . Table 2 displays the linear regression data for the calibration curve of eugenol.

\section{Accuracy as recovery}

Accuracy was investigated by analyzing three concentrations of the standard drug solution previously analyzed using standard addition technique. The recovery studies were carried out to check the sensitivity of the method to estimate eugenol. The standard addition technique was carried out by adding 50\%, $100 \%$, and $150 \%$ of eugenol concentration in the sample. The percentage recoveries of the three concentrations were found to be $99.60 \%$ to $101.07 \%$, which is indicative of high accuracy. The values of percentage recovery and \%RSD are displayed in Table 3 . The mean percentage recovery values, close to $100 \%$, and their low \%RSD values indicated high accuracy of the analytical method.

\section{Precision}

The repeatability of developed HPLC method, by intraday assay, is expressed in the terms of \%RSD, and the results (Table 4) demonstrated the repeatability of the method. The interday variation of eugenol at three different concentration levels of 20,100, and $600 \mu \mathrm{g} \mathrm{mL}$ establishes the intermediate precision of the method. The low values of \%RSD for repeatability and intermediate precision suggested an excellent precision of the developed HPLC method.

\section{Specificity}

The specificity of the developed method for the analysis of eugenol in the nanoemulsion gel and nanoparticle samples was confirmed by comparing the spectra obtained in the standard and sample analyses (Figure 3). The peak start, peak apex, and peak end positions of these spectra were matching.

\section{Robustness}

Robustness was studied by introducing small changes in the mobile phase ratio, flow rate, and detection wavelength of analysis. The standard deviation and \%RSD of peak area and retention time $\left(R_{\mathrm{t}}\right)$ was calculated and

Table 4 Repeatability and intermediate precision of HPLC method

\begin{tabular}{|c|c|c|c|c|}
\hline \multirow[t]{2}{*}{ Concentration $\left(\mu \mathrm{g} \mathrm{mL}^{-1}\right)$} & \multicolumn{2}{|c|}{ Repeatability $(n=3)$} & \multicolumn{2}{|c|}{ Intermediate precision $(n=3)$} \\
\hline & Mean peak area \pm SD & \%RSD & Mean peak area \pm SD & \%RSD \\
\hline 20 & $468283.0 \pm 3410.6$ & 0.73 & $467144.7 \pm 3398.0$ & 0.73 \\
\hline 100 & $2213959.7 \pm 11480.9$ & 0.52 & $2213539.0 \pm 8008.9$ & 0.36 \\
\hline 600 & $12800060.3 \pm 45178.8$ & 0.35 & $12778185.3 \pm 40768.0$ & 0.32 \\
\hline
\end{tabular}




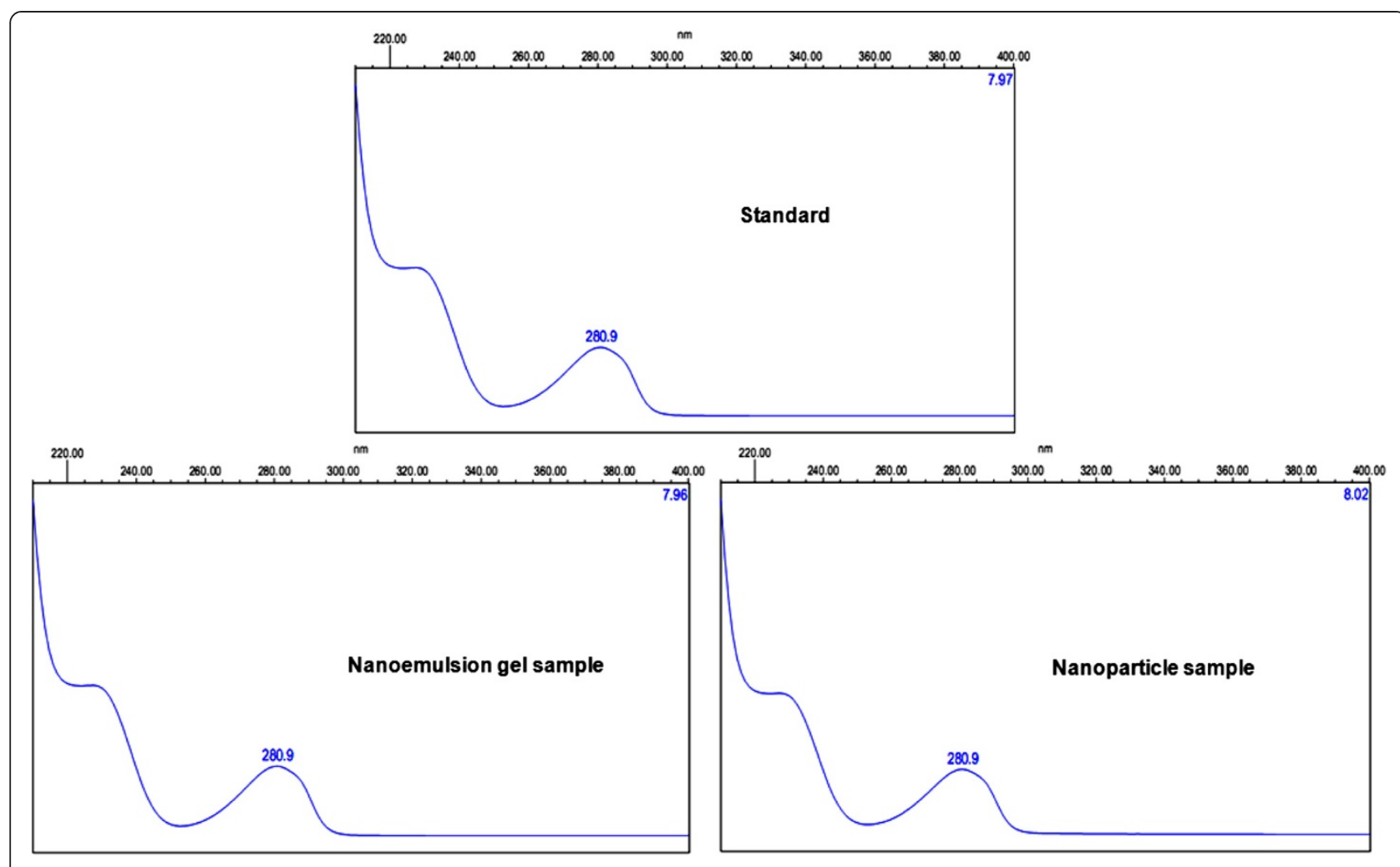

Figure 3 UV absorption spectra of eugenol in standard, nanoemulsion gel sample, and nanoparticle sample.

listed in Table 5. The low values of \%RSD show the robustness of the method.

\section{Detection and quantitation limits}

The DL and QL were determined as per the ICH Guidelines Q2(R1) (2005) and were found to be 0.44 and 1.34 $\mu \mathrm{g} \mathrm{mL}^{-1}$, respectively.

\section{Conclusions}

The RP-HPLC-PDA system with C18 reversed-phase column $(250 \times 4.6 \mathrm{~mm}$, particle size $5 \mu \mathrm{m})$ was used in this study. Acetonitrile and water in the ratio of 1:1 $(v / v)$ was chosen as the mobile phase, and a detection wavelength of $280 \mathrm{~nm}$ was used with a

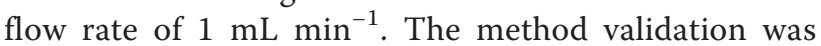
performed according to the guidelines of the

Table 5 Robustness data of the HPLC method

\begin{tabular}{|c|c|c|c|c|c|c|c|}
\hline \multirow[t]{2}{*}{ Parameter } & \multicolumn{3}{|c|}{ Study condition } & \multirow[t]{2}{*}{ Mean area \pm SD } & \multirow[t]{2}{*}{$\%$ RSD of area } & \multirow[t]{2}{*}{$R_{\mathrm{t}} \pm \mathrm{SD}$} & \multirow[t]{2}{*}{$\%$ RSD of $R_{t}$} \\
\hline & Original & Used & Level & & & & \\
\hline \multirow[t]{3}{*}{ Mobile phase ratio (ACN/water) } & $50: 50$ & $48: 52$ & -1 & $2218634.9 \pm 6686.7$ & 0.30 & $7.968 \pm 0.024$ & 0.30 \\
\hline & & $50: 50$ & 0 & & & & \\
\hline & & $52: 48$ & +1 & & & & \\
\hline \multirow[t]{3}{*}{ Flow rate $\left(\mathrm{mL} \mathrm{min}^{-1}\right)$} & 1.0 & 0.9 & -1 & $2216384.3 \pm 8147.4$ & 0.37 & $7.958 \pm 0.068$ & 0.85 \\
\hline & & 1.0 & 0 & & & & \\
\hline & & 1.1 & +1 & & & & \\
\hline \multirow[t]{3}{*}{ Detection wavelength $(\mathrm{nm})$} & 280 & 278 & -1 & $2214941.3 \pm 13356.9$ & 0.60 & $7.967 \pm 0.030$ & 0.38 \\
\hline & & 280 & 0 & & & & \\
\hline & & 282 & +1 & & & & \\
\hline
\end{tabular}

$n=3$ at each level. Concentration $=100 \mu \mathrm{g} \mathrm{m} \mathrm{L}^{-1}$. 
International Conference on Harmonization (ICH). HPLC method for the quantification of eugenol was successfully developed and validated. The method was validated in terms of linearity and range, accuracy, precision, specificity, robustness, detection limit, and quantitation limit. The DL and QL were determined as per the $\mathrm{ICH}$ guidelines and were found to be 0.44 and $1.34 \mu \mathrm{g} \mathrm{mL}^{-1}$, respectively. The developed RP-HPLC-PDA could be successfully employed for the quantification of eugenol in its nanoemulsion gel and nanoparticles.

\section{Competing interests}

The authors declared that they have no competing interests.

\section{Authors' contributions}

$\mathrm{KP}, \mathrm{SHA}$ and JA proposed the idea and design the experiment. KP and JA carried out the preparation of nanoemulsion and nanoparticles. UKI assisted in framing the experiments. UKI prepared standards and samples for analysis. YTK and SA carried out the HPLC analysis of the samples and standard. Al authors participated in the preparation of the manuscript. All authors read and approved the final manuscript.

\section{Acknowledgements}

Pramod K gratefully acknowledges Indian Council of Medical Research (ICMR), New Delhi, India, for providing Senior Research Fellowship (No. 35/3/ 10/NAN/BMS)

\section{Author details}

'Department of Pharmaceutics, Faculty of Pharmacy, Jamia Hamdard, Hamdard Nagar, New Delhi - 110 062, India. ²Department of Pharmacognosy \& Phytochemistry, Faculty of Pharmacy, Jamia Hamdard, Hamdard Nagar, New Delhi - 110 062, India.

Received: 18 May 2013 Accepted: 10 October 2013

Published: 28 Oct 2013

\section{References}

Chen F, Shi Z, Neoh KG, Kang ET (2009) Antioxidant and antibacterial activities of eugenol and carvacrol-grafted chitosan nanoparticles. Biotechnol Bioeng 104(1):30-39

Dighe W, Gursale AA, Sane RT, Menon S, Patel PH (2005) Quantitative determination of eugenol from Cinnamomum tamala Nees and Eberm: leaf powder and polyherbal formulation using reverse phase liquid chromatography. Chromatographia 61:443-446

Gomes C, Moreira RG, Castell-Perez E (2011) Poly (DL-lactide-co-glycolide) (PLGA) nanoparticles with entrapped trans-cinnamaldehyde and eugenol for antimicrobial delivery applications. J Food Sci 76(2):N16-N24

ICH Guidelines Q2(R1) (2005) Validation of analytical procedures: text and methodology, http://www.ich.org/fileadmin/Public_Web_Site/ICH_ Products/Guidelines/Quality/Q2_R1/Step4/Q2_R1_Guideline.pdf. Accessed 10 Mar 2011

Jadhav BK, Khandelwal KR, Ketkar AR, Pisal SS (2004) Formulation and evaluation of mucoadhesive nanocapsules containing eugenol for the treatment of periodontal diseases. Drug Dev Ind Pharm 30:195-203

Kriegel C, Kit KM, McClements DJ, Weiss J (2010) Nanofibers as carrier systems for antimicrobial microemulsions: II: release characteristics and antimicrobial activity. J Appl Polym Sci 118:2859-2868

Levi L, Walker GC, Pugsley LI (1964) Quality control of pharmaceuticals. Can Med Assoc J 91(15):781-785

Li Y, Sun Z, Zheng P (2004) Determination of vanillin, eugenol and isoeugenol by RP-HPLC. Chromatographia 60:709-713

Pokharkar VB, Shekhawat PB, Dhapte W, Mandpe LP (2011) Development and optimization of eugenol loaded nanostructured lipid carriers for periodontal delivery. Int J Pharm Pharm Sci 3:138-143

Pramod K, Ansari SH, Ali J (2010) Eugenol: a natural compound with versatile pharmacological actions. Nat Prod Commun 5(12):1999-2006
Pramod K, Shanavas S, Ansari SH, Ali J (2012) Eugenol nanodroplet gel as novel biomaterial in nanomedicine. Adv Sci Lett 10:1-13

Pramod K, Ansari SH, Ali J (2013) Fabrication and tailoring of eugenol loaded polycaprolactone nanoparticles using response surface methodology. Adv Sci Eng Med 5(11):1166-1175

Reis CP. Neufeld RJ, Ribeiro AJ, Veiga F (2006) Nanoencapsulation I: methods for preparation of drug-loaded polymeric nanoparticles. Nanomedicine 2:8-21

\subsection{6/2093-3371-4-16}

Cite this article as: Pramod et al:: Development and validation of RP-HPLC-PDA method for the quantification of eugenol in developed nanoemulsion gel and nanoparticles. Journal of Analytical Science and Technology 2013, 4:16

\section{Submit your manuscript to a SpringerOpen ${ }^{\odot}$ journal and benefit from:}

- Convenient online submission

- Rigorous peer review

- Immediate publication on acceptance

- Open access: articles freely available online

- High visibility within the field

- Retaining the copyright to your article

Submit your next manuscript at $\gg$ springeropen.com 